\title{
The Development Path of Leisure and Cultural Destination Tourism around Tai'an
}

\author{
Cheng-Lei LIANG $^{1 \text {, a }}$ \\ ${ }^{1}$ Cheng-lei Liang, Dongfang College, ShanDong University of Finance and Economics, Taian, \\ China, 271000 \\ aemail:liangchenglei@163.com
}

Keyword: Around Tai'an, Culture and leisure tourism, Development path.

\begin{abstract}
Through the investigation of the natural ecological factors and cultural elements around Tai'an, in view of the analysis of the development value and development difficulty of resource elements, projects the overall development direction which on the basic of type rural leisure tourism, as the forerunner by ecological experience leisure tourism and theme cultural leisure tourism, take the culture of ancient town leisure tourism as the core.
\end{abstract}

\section{Introduction}

With the increase of income of urban residents in China, the demand for leisure is becoming more and more intense, the leisure consumption of modern urban residents will present the trend of combining cultural experience with leisure, in particular, leisure tourism destinations with strong cultural and creative experience are becoming more and more popular among urban residents.

However, the research on the related theories has lagged behind the development of practice and the needs of the society.

Taking culture and leisure tourism destination around Tai'an as the research object, this paper probes into the development mode of culture and leisure tourism around city, which is of great value for promoting the quality improvement and product innovation of the culture and leisure tourism area in the suburb of the city.

\section{Investigation and Analysis of Social Economic, Culture and Leisure Resources around Tai'an Regional Advantage}

The suburbs of Tai'an, mainly include the suburbs of Daiyue District,, are in the middle of the "Taishan-the Yellow River - Confucius" tourist hotline. North is adjacent to Taishan District, Licheng District, Changqing county and Zhangqiu city. The East is on the border with Laiwu city and Xintai City, the South and Ningyang county are separated from a Wenchuan River, and the west is connected with Feicheng city.

The convenience of transportation in the region is favorable for the absorption of popularity, especially for the development of the tertiary industry, such as modern service industry and leisure industry.

\section{Status of Ecological Resources}

Tai'an tourism is based on the Taishan scenic area as the core, radiating to the surrounding cities and counties under its jurisdiction, driving the development of such tourist areas as Mount Lai, Mount Wushan, Lianshan, Niu Shan and Dongping Lake.

The suburb of Tai'an is rich in natural resources and abundant natural ecological resources. It is not only an important fresh air supply area in Tai'an, but also an important support for developing various industries, especially tourism, recreation and health industry.

What's more, it is very close to the center of the city, which provides an opportunity for the full exploitation and utilization of this resource. It can aim at the business opportunities of the elderly, 
such as health care, and family weekend getaway and so on, and has great potential in the green health industry.

\section{Cultural Resources}

Tai'an is one of the birthplaces of China's national civilization and a famous historical and cultural city. As early as half a million years ago, there was a human existence and reproduction. The Xintai people 50,000 years ago have stepped into the Homo sapiens phase. The brilliant Dawenkou culture gave birth to it more than 5,000 years ago and has become a symbol of the history of Chinese nation civilization An important milestone.

As the ancients worship of the sun and the mountains, from Yao and Shun to Qin and Han Dynasties, until the Ming and Qing Dynasties, stretches for thousands of years, Mount Tai became the ancient mountain god sacrificial day.

With the Fengshan culture, Taishan has been deified, the famous literati come in a throng to Taishan and Tai'an, leaving many places of historic interest and scenic beauty.

In 2007, the State Council formally issued the document and agreed to list the city of Tai'an as a national historical and cultural city. The document states that the city of Tai'an has a long history of development with rich cultural relics, well-preserved historical relics, magnificent natural scenery, and an important history , Science, artistic value.

The suburb of Tai'an has profound regional culture, good ecological scenery and simple folk customs, and has outstanding folk customs. All these provide exceptional conditions for developing tourism, especially leisure agriculture and rural tourism.

In the outskirts of Tai'an, there are traditional temple fair culture, good ecological scenery and simple folk customs, plus sightseeing and picking, with outstanding folk customs and characteristics. How to make use of these important features and brands is one of the important key points in the development of the suburban towns in Tai'an.

Making full use of the advantages of the characteristic planting industry in the field and developing the added value of the characteristic planting industry, identifying the characteristic agriculture with creativity as the core is the most favorable way for the differential development in the suburbs of Tai'an.

\section{Tourism Development}

In recent years, the tourism industry in Tai'an has achieved a steady and rapid development. In 2016, the tourism market in Tai'an won another breakthrough. A total of 62,782,000 domestic and foreign tourists were received, with a total tourist spending of 66.164 billion Yuan, an increase of 8.4\% and 13.6\%over the previous year respectively. Among them, domestic tourists 62.397 million passengers, achieving consumption of 62.96 billion Yuan, an increase of $8.5 \%$ and $13.7 \%$.

The scenic spots in the suburb of Tai'an received 5 million 841 thousand visitors, and the income of tickets was 650 million Yuan. The total investment of village and town construction reached 2 billion 160 million Yuan in the whole year. New towns and village roads were newly built and maintained for 7 million 360 thousand square meters, and 67 new towns and village parks and fitness centers were added.

In 2016, the Tianyi Lake Holiday Resort passed the inspection of the national 4A scenic spot, and Daiyue District newly created 3 national 3A scenic spots and created 2 national ecological towns and 2 provincial ecological towns and 6 provincial-level ecological villages. Smoothly through the national health city review.

Based on the analysis of culture and leisure tourism resources in the suburbs of Tai'an, from the perspective of resource level, the cultural resources based on the ancient town have the highest grade, followed by the natural ecological resources and finally the industrial resources.

According to the scale and quantity of resources, industrial resources with characteristic ecological agriculture as the core are the most abundant, followed by ecological resources and the last is cultural resources. 
From the distribution characteristics of resources, the distribution of cultural resources is scattered, showing a punctuate distribution, while industrial resources and ecological resources are flaky distribution[1].

\section{The Choice of the Development Direction of Culture and Leisure Tourism around Tai'an}

The development value of culture and leisure tourism in the suburb of Tai'an is evaluated from the characteristics of the resource elements, the difficulty of development and the potential development value.

From the following table 1, it can be seen that the characteristics of the natural ecological elements are more prominent, the development difficulty is relatively small, and the recent development value is relatively large.

The characteristics of cultural elements are the most outstanding, but related to the block transformation and other factors, have high investment cost, greater development difficulty and potential value, but the value of recent development is relatively small.

In the factors of industrial economy, compared with a large number of rural leisure tourism destinations around Tai'an, the characteristics are not very prominent[2].

Table 1 the value evaluation of the core elements around Tai'an

\begin{tabular}{|l|l|l|l|l|}
\hline The type of resource & $\begin{array}{l}\text { Description of resource } \\
\text { characteristics }\end{array}$ & Characteristic & $\begin{array}{l}\text { Difficulty of } \\
\text { development }\end{array}$ & $\begin{array}{l}\text { potential } \\
\text { value }\end{array}$ \\
\hline $\begin{array}{l}\text { natural ecological } \\
\text { elements }\end{array}$ & $\begin{array}{l}\text { Forest Park, mountain, } \\
\text { water }\end{array}$ & lowest & lowest & lowest \\
\hline Cultural elements & $\begin{array}{l}\text { ancient town, mount Tai } \\
\text { culture }\end{array}$ & highest & highest & highest \\
\hline Industrial economic & $\begin{array}{l}\text { ecological agriculture, } \\
\text { theme park }\end{array}$ & lowest & lowest & higher \\
\hline
\end{tabular}

Considering the factors such as resource conditions, cultural leisure needs and market competition conditions, projects the overall development direction which on the basic of type rural leisure tourism, as the forerunner by ecological experience leisure tourism and theme cultural leisure tourism, take the culture of ancient town leisure tourism as the core, in order to achieve the balance between short-term and long-term interests, and achieve the comprehensive value of natural ecological, cultural and agricultural resources and other factors, and give consideration to the needs of balanced development of all villages[3].

For ecological tourism products, we should rely on the ecological resources such as Mountain Culai National Forest Park to develop ecological experience leisure tourism product system with outdoor leisure sports, ecological sightseeing, ecological leisure and vacation, entertainment and ecological science as the core[4].

For the development of ancient town culture and leisure tourism product, the key is to repair and protect the ancient town and ancient historical relics carrier, relying on the historical town, implanted urbanization leisure consumption content, forming the characteristic industry format and product system.

The core of the development of rural culture and leisure tourism products is to build consumption experience products and special housing, catering and entertainment activities based on the local agricultural production tradition, such as agricultural sightseeing, picking, agricultural products handcraft experience, agricultural creativity and so on.

The theme cultural leisure tourism destination is a theme amusement activity or experience carrier as the core attraction, which integrates theme entertainment, cultural experience, leisure and other functions. In addition, it also meets the demand for entertainment experience such as music and drama. Through more realistic scene and interactive scene design, the art experience is more impactful.

For theme culture leisure tourism destinations, the theme selection generally focuses on satisfying some entertainment needs of urban consumers. Through the design of devices and scenes, 
it can satisfy the release of tourists' stimulation and relieve the pressure[5].Around the theme of man-made projects, setting up special catering, subject accommodation, transportation and other projects, forming a full and holographic theme entertainment experience process.

\section{Reference}

[1]Li liang wen.The Experiences and Inspirations of Overseas Rural Tourism Development to Our Country[J].Tourism Tribune,2015,(01):91-92.

[2]Zhou ji xia, Su wei ci.Study on the Sustainable Development of Rural Tourism in Chongqing's Recreation Belt around the city[J].Rural Economy,2007(7),3640.

[3]Shen he jiang,Shen shao ling.Study on the Structure Layout and Development Model of Urban Leisure Sightseeing Agricultural Tourism[J]. Journal of Business Economics,2007(11).

[4]Wu bi hu,Ma xiao meng.The Spatial Structure of Rural Tourist Destinations around Chinese Cities[J].Scientia Geographica Sinica,2004,24(6),757-763.

[5]Ji wei.Study on the Evolution of Rural Tourism Community from the Perspective of Space[D].East China Normal University,2014, 40-42. 